\title{
Produção de feijão-caupi e gergelim consorciado com mamoneira no Semiárido paraibano
}

\section{Production of cowpea and sesame intercropped with castor bean in semiarid region of Paraiba}

\author{
Guilherme de Freitas Furtado ${ }^{1}$, Anielson dos Santos Souza ${ }^{2}$, Rodolfo Rodrigo de Almeida Lacerda ${ }^{3}$, Lúcia Helena Garófalo \\ Chaves $^{4}$, José Raimundo de Sousa Júnior ${ }^{5}$, Jônatas Raulino Marques de Sousa ${ }^{6}$
}

Resumo: Objetivou-se avaliar os componentes de produção do feijão-caupi e gergelim, consorciado com a mamoneira no semiárido paraibano. O experimento foi desenvolvido no período de março a novembro de 2011 em condições de campo em Pombal, Paraíba. Realizou-se sob delineamento experimental em blocos ao acaso com três sistemas de cultivo em dois ensaios experimentais: feijão-caupi (cv. BRS Novaera) e gergelim (cv. BRS Seda) em monocultivo, consórcio com mamona cv. IAC 2028 e consórcio com mamona cv. BRS Nordestina, com 4 repetições, totalizando 12 parcelas experimentais em cada ensaio. O consórcio com a mamoneira reduz os componentes de produção e produtividade do feijão-caupi e gergelim, sendo a cv. BRS Nordestina mais competitiva. Considerando as variáveis estudadas, a melhor opção para cultivo consorciado do feijão-caupi ou gergelim na região é a cv. IAC 2028.

Palavras-chave: Ricinus communis L., Sesamum indicum L., sistema de cultivo, Vigna unguiculata (L.) walp.

\begin{abstract}
The objective was to evaluate yield components of cowpea and sesame grown as secondary crops, intercropping with castor bean in the semiarid region of Paraiba. The experiment was carried out from March to November 2011 under field conditions in Pombal, Paraíba state. Three experimental systems were used in a randomized block design in two experimental trials: cowpea (cv. BRS Novaera) and sesame (cv. BRS Seda) in monoculture, intercropping with castor bean cv. IAC 2028 and intercropping with castor bean cv. BRS Nordestina, with 4 replicates, totaling 12 experimental plot in each trial. The intercrop with castor bean reduces yield components and yield of cowpea and sesame, with an cv. BRS Nordestina more competitive. Considering the variables studied, the best option for intercropping cowpea or sesame in the region is the cv. IAC 2028 .
\end{abstract}

Key words: cropping system, Ricinus communis L., Sesamum indicum L., Vigna unguiculata (L.) walp.

\footnotetext{
*Autor para correspondência

Recebido para publicação em 15/01/2017; aprovado em 03/03/2017

${ }^{1}$ Eng. Agro. doutorando do programa de pós-graduação em Engenharia Agrícola, UAEA/UFCG, Campina Grande-PB, gfreitasagro@gmail.com.

${ }^{2}$ Eng. Agro. Dr. Sc., Professor Adjunto da Unidade Acadêmica de Ciências Agrárias - CCTA/UFCG - Universidade Federal de Campina Grande, Pombal-

PB. E-mail: anielson@ccta.ufcg.edu.br

${ }^{3}$ Eng. Agro. doutorando do programa de pós-graduação em Agronomia /fitotecnia, PGFITO/UFERSA, Mossoró-RN, rodolfo-lacerda@ hotmail.com

${ }^{4}$ Eng(a). Agro. Dra. Sc., Professora titular da Universidade Federal de Campina Grande, UAEA/UFCG, lhgarofalo@ hotmail.com

${ }^{5}$ Eng. Agro. Mestre em Engenharia Agrícola, UAEA/UFCG, Campina Grande-PB, jrssjunior@gmail.com.

${ }^{6}$ Eng. Agro. doutorando do programa de pós-graduação em Engenharia Agrícola, UAEA/UFCG, Campina Grande-PB, jonatasraulyno@gmail.com.
} 


\section{INTRODUÇÃO}

O consórcio de culturas é uma das práticas mais comuns utilizadas nos sistemas agrícolas sustentáveis, que tem um papel importante no aumento da produtividade e da estabilidade do rendimento, a fim de otimizar a utilização dos recursos e dos fatores ambientais (ALIZADEH et al., 2009). Essa prática consiste basicamente na exploração simultânea de duas ou mais culturas na mesma área de plantio, ocorrendo intensificação da exploração agrícola no tempo e no espaço. Segundo Lithourgidis et al. (2011), os sistemas consorciados proporcionam vantagens em relação ao monocultivo por aumentar o rendimento das culturas em virtude da utilização mais eficiente os recursos disponíveis.

O feijão-caupi (Vigna unguiculata (L.) walp.) é uma leguminosa de elevado valor socioeconômico para o Brasil, como suprimento alimentar, na fixação de mão de obra no campo e como componente da produção agrícola (BEZERRA et al., 2008; ROCHA et al., 2009). Na Paraíba, o feijão é cultivado em quase todas as microrregiões, totalizando uma área de 174,2 mil hectares, produção de 37,8 mil toneladas e ocupando o quinto lugar em área plantada no Nordeste (IBGE, 2011). É amplamente cultivado por pequenos agricultores em sistema de consórcio com outras culturas, como, milho, mandioca e, mais recentemente, com a mamona. Nesse sentido, o consórcio dessa leguminosa tornase uma alternativa viável para a produção em pequenas propriedades, notadamente no semiárido paraibano.

O gergelim (Sesamum indicum L) é uma oleaginosa muito cultivada no mundo por possuir óleo de qualidade superior às demais oleaginosas comumente usadas para alimentação humana (LAYANEZ-GARSABALL; MÉNDEZNATERA, 2006). Segundo dados da FAO (2012) a produção mundial estimada foi de 4,16 milhões de toneladas, obtidas em 8,05 milhões de hectares, com produtividade de $517,5 \mathrm{~kg}$ $\mathrm{ha}^{-1}$, sendo China, Índia e Myanmar responsáveis por 43,93\% da produção mundial. O Brasil é um pequeno produtor, com 6 mil toneladas produzidas em 10 mil hectares e rendimento de $600 \mathrm{~kg} \mathrm{ha}^{-1}$. É bastante produtivo em regiões com precipitações entre 400 a $650 \mathrm{~mm}$, sendo muito tolerante a curtos períodos de estiagem o que torna uma cultura em potencial para o semiárido brasileiro (FERREIRA; BELTRÃO, 2013).

A mamoneira (Ricinus communis L.) é uma planta rústica, que consegue alcançar elevada produção de biomassa em lugares de baixa precipitação pluvial (COSCIONE; BERTON, 2009). O cultivo convencional, entretanto, expõe o ambiente de cultivo a problemas de erosão e de interferência de plantas daninhas pela menor taxa de cobertura vegetal obtida. Problemas dessa natureza podem ser minimizados com o cultivo intercalar de outras espécies. Conforme Azevedo et al. (2007a), o consórcio entre culturas de hábitos de crescimento diferentes tem sido muito utilizado em regiões tropicais como estratégia para mitigar os efeitos da irregularidade climática.

Algumas pesquisas têm evidenciado vantagens do sistema consorciado entre mamoneira e outras culturas, quais sejam: mamona + feijão-caupi, milho ou sorgo (AZEVEDO et al., 2007a); mamona + gergelim (BELTRÃO et al., 2010b); mamona + amendoim (BELTRÃO et al., 2010a; DUTRA et al., 2015); mamona + gergelim ou milho (PINTO et al., 2011); mamona + feijão-caupi ou milho (OLIVEIRA FILHO, et al., 2016).
$\mathrm{Na}$ literatura as informações disponíveis sobre sistemas consorciados com a mamoneira não refletem o desempenho produtivo das culturas em consórcio. Nesse sentido, a avaliação desses materiais, sobressai em importância, especialmente para melhor inferir-se sobre o seu potencial de produtividade, quando se busca maximizar a eficiência de ambas as culturas.

Diante do exposto, objetivou-se avaliar os componentes de produção do feijão-caupi e gergelim, cultivados como culturas secundárias, consorciado com a mamoneira em condições de semiárido nordestino.

\section{MATERIAL E MÉTODOS}

O estudo foi conduzido em condições de campo, na Comunidade Monte Alegre, localizado no município de Pombal, Paraíba, situado a $06^{\circ} 46^{\prime}$ de latitude sul e $37^{\circ} 48^{\prime}$ de longitude oeste, com altitude de $184 \mathrm{~m}$ (BELTRÃO et al., 2005) no período de março a novembro de 2011. O clima, segundo a classificação de Köppen, é Aw', ou seja, quente e úmido com chuvas de verão/outono, precipitações pluviais anuais em torno de $800 \mathrm{~mm}$ e amplitude térmica inferior a $5^{\circ}$ C (PEEL et al., 2007). No período experimental a precipitação pluvial foi de $563 \mathrm{~mm}$ (Figura 1), com distribuição irregular, concentrando-se nos meses de março a julho e de outubro a novembro.

Figura 1. Precipitação pluvial na área experimental durante o ano de 2011, comunidade Monte Alegre. Pombal, Paraíba



Fonte: EMATER (2011)

O solo da área foi classificado como Neossolo Flúvico. Previamente à semeadura das culturas foi realizada a amostragem do solo na profundidade de $0-30 \mathrm{~cm}$ para fins de caracterização físico-química do solo e da área de cultivo (EMBRAPA, 2006). Realizaram-se amostragens simples para obtenção de uma amostra composta cujos resultados foram: $\mathrm{pH}\left(\mathrm{CaC}_{12}\right)=6,17 ; \mathrm{P}=11 \mathrm{mg} \mathrm{dm}{ }^{-3} ; \mathrm{K}^{+}=0,23 \mathrm{cmolc} \mathrm{dm}^{-3}$; $\mathrm{Al}^{3+}=0,0$ cmolc dm ${ }^{-3} ; \mathrm{Ca}^{2+}=4,10$ cmolc dm${ }^{-3} ; \mathrm{Mg}^{2+}=2,20$ cmolc dm ${ }^{-3} ; \mathrm{Na}^{+}=0,05 \mathrm{cmolc} \mathrm{dm}^{-3} ; \mathrm{H}+\mathrm{Al}=2,15$ cmolc dm ${ }^{3}$; matéria orgânica $=26 \mathrm{~g} \mathrm{~kg}^{-1}$; areia, silte e argila corresponderam a 755; 87 e $158 \mathrm{~g} \mathrm{~kg}^{-1}$, respectivamente.

$\mathrm{O}$ delineamento experimental utilizado foi o de blocos casualizados, com três sistemas de cultivo (monocultivo; consórcio com mamona cv. IAC 2028 e consórcio com mamona cv. BRS Nordestina) e duas culturas, feijão-caupi (cv. BRS Novaera) e gergelim (cv. BRS Seda), com quatro repetições, totalizando 12 parcelas experimentais em cada ensaio com ruas entre blocos e parcelas de 1,0 m. As parcelas 
consorciadas foram compostas por duas fileiras de feijãocaupi ou gergelim com $7 \mathrm{~m}$ de comprimento intercalado entre três fileiras de mamona espaçadas de $2,0 \mathrm{~m}$, os quais foram semeados 15 dias após a semeadura da mamoneira.

As parcelas em monocultivo foram constituídas de 3 fileiras de $7 \mathrm{~m}$ nos seguintes espaçamentos: feijão-caupi - 0,5 x $0,5 \mathrm{~m}$ (40.000 plantas ha $\left.^{-1}\right)$ e gergelim - 0,5 x $0,1 \mathrm{~m}$ (200.000 plantas ha $\left.{ }^{-1}\right)$. No consórcio a população de plantas para o feijão-caupi e gergelim foi a mesma para o monocultivo e para a mamona foi de 5.000 plantas $^{-1} \mathrm{p}^{-1}(2 \times 1$ $\mathrm{m})$.

O preparo do solo foi realizado de forma convencional por meio de aração e gradagem a uma profundidade de $30 \mathrm{~cm}$, cinco dias antes da semeadura. A mamona e o feijão-caupi foram semeados em covas com 3 a $5 \mathrm{~cm}$ de profundidade, com 3 sementes por cova. O gergelim foi semeado em linha com 3 a $5 \mathrm{~cm}$ de profundidade, com 20 sementes $\mathrm{m}^{-1}$.

A adubação foi realizada em covas para a mamona e feijão-caupi e em linha para o gergelim, sendo aplicados 60 $\mathrm{kg} \mathrm{ha}^{-1}$ de nitrogênio, $40 \mathrm{~kg} \mathrm{ha}^{-1}$ de fósforo e $40 \mathrm{~kg} \mathrm{ha}^{-1} \mathrm{de}$ potássio, respectivamente, utilizando-se como fontes ureia, superfosfato simples e cloreto de potássio, conforme valores indicados pela UFC (1993).

A adubação de fundação foi realizada no momento da semeadura aplicando-se todo o fósforo e potássio e 1/3 do nitrogênio recomendado. $\mathrm{O}$ restante do $\mathrm{N}$ foi parcelado em duas vezes e aplicado em cobertura aos 40 e 60 dias após a semeadura (DAS).

A coleta dos dados do feijão-caupi e gergelim foram realizados, respectivamente aos 80 e 100 DAS (final do ciclo), coletando-se uma área de $1 \mathrm{~m}$ das duas fileiras centrais nas parcelas em monocultivo e em consórcio.

No feijão-caupi foram avaliados os dados de comprimento de vagem $(\mathrm{mm})$; diâmetro de vagem $(\mathrm{mm})$; número de grãos por vagem; massa de 100 grãos mediante metodologia proposta por Brasil (2009); e produtividade de grãos $\left(\mathrm{kg} \mathrm{ha}^{-1}\right)$

No gergelim foram avaliados os dados de altura de inserção do primeiro fruto $(\mathrm{cm})$; número de frutos por planta; e produtividade de grãos $\left(\mathrm{kg} \mathrm{ha}^{-1}\right)$.

Os dados obtidos foram submetidos à análise da variância pelo teste ' $F$ ', e quando verificada significância dos tratamentos, realizou-se o teste de Tukey $(\mathrm{p} \leq 0,05$ e $\mathrm{p} \leq$ 0,01), utilizando-se do software estatístico SISVAR (FERREIRA, 2011).

\section{RESULTADOS E DISCUSSÃO}

Os maiores valores dos componentes de produção do feijão-caupi foram obtidos quando se cultivou em sistema de monocultivo (Figura 2). No entanto, não houve diferença significativa no sistema consórcio com a cv. IAC 2028, provavelmente, porque este cultivar possui porte baixo, inferior a do cv. BRS Nordestina, limitando de forma menos expressiva os recursos do meio. Segundo Portes (1996) a competição por água, nutrientes e luz afeta o rendimento das culturas consorciadas, sendo a luz um dos principais, senão o principal fator limitante e que constitui importante empecilho à utilização de consórcios. Costa et al. (2010) citam que o sistema consorciado interfere negativamente em todas as características agronômicas do feijoeiro.

Figura 2. Comprimento de vagens - cm (A), diâmetro de vagens - mm (B), número de grãos por vagem $(\mathrm{C})$, massa de cem grãos - g (D) e produtividade de grãos $\left(\mathrm{kg} \mathrm{ha}^{-1}\right)(\mathrm{E})$ do feijão-caupi cultivado em diferentes sistemas de cultivo


Sistemas de Cultivo

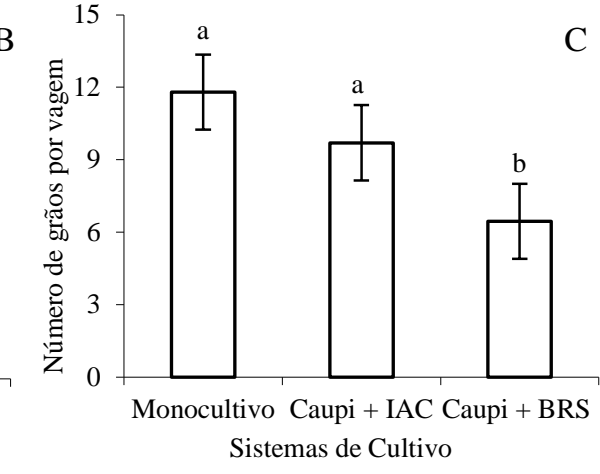

$\mathrm{E}$

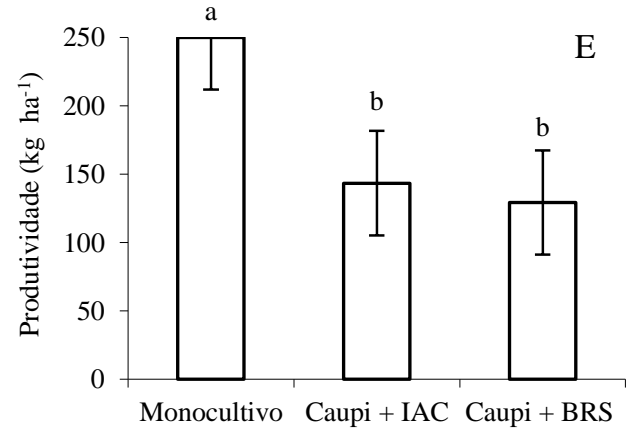

Sistemas de Cultivo

As letras diferentes em cada coluna indicam diferença estatística entre as médias do tratamento pelo teste de Tukey $(p \leq 0,05)$

Considerando os sistemas consorciados, os menores valores foram obtidos no consórcio com a cv. BRS
Nordestina havendo uma redução de $27,67 \%$ para o comprimento de vagem (CV) (Figura 2A), 13,23\% para 
diâmetro de vagem (DV) (Figura 2B), 45,34\% para o número de grãos por vagem (NGV) (Figura 2C), 16,72\% para a massa de 100 grãos (Figura 2D) em relação ao monocultivo. Estes resultados possivelmente ocorreram em virtude da competição interespecífica indicando também que a cv. BRS Nordestina é mais competitiva que a cv. IAC 2028. De acordo com Araújo et al. (2014) a competição interespecífica entre as culturas envolvidas em um agroecossistema consorciado, em geral, reduz, em maior ou menor grau, o rendimento de cada uma delas em cultivo isolado.

A maior produtividade de grãos foi obtida no monocultivo do feijão-caupi (250 $\mathrm{kg} \mathrm{ha}^{-1}$ ) (Figura 2E), no entanto, esse valor é muito abaixo da média Nordestina que foi de $584 \mathrm{~kg} \mathrm{ha}^{-1}$ (CONAB, 2011). Santos et al. (2011) avaliando o comportamento de cultivares de feijão-caupi nas condições edafoclimáticas do Brejo Paraibano obtiveram produtividade média de grãos secos com a cultivar BRS Marataoã de $1.232 \mathrm{~kg} \mathrm{ha}{ }^{-1}$. Esse resultado pode estar relacionado à baixa precipitação pluviométrica ocorrida no período de condução do experimento (563 mm) (Figura 1). Com relação aos sistemas consorciados, verifica-se redução de produtividade de $42,6 \%$ e $48,3 \%$, respectivamente para o consórcio com a cv. IAC 2028 e BRS Nordestina. Tais resultados corroboram com os obtidos por Costa e Silva
(2008), que observaram redução de rendimento do feijoeiro entre 50 e $80 \%$ quando cultivado em sistema consorciado. Bhatti et al. (2013) verificaram reduções de rendimento do feijoeiro entre 13 e $38 \%$ quando cultivado em consórcio com gergelim. Albuquerque et al. (2015) observaram reduções de $52,82 \%$ na produtividade do feijão-caupi com mandioca.

A altura de inserção do primeiro fruto (AIF) não diferiu estatisticamente entre os sistemas de cultivo, observando-se um valor médio de 60,48 cm (Figura 3A), sendo este superior aos valores reportados por Pereira et al. (2002), os quais verificaram AIF de 52,08 cm. Em termos absolutos observase conforme os resultados da Figura $3 \mathrm{~A}$ maior competição entre o gergelim e a cultivar BRS Nordestina, verificando-se uma redução de $11,82 \%$ e $8,05 \%$ da AIF, quando se compara as plantas cultivadas em sistema de monocultivo e consorciadas com a cv. IAC 2028, respectivamente.

O maior número de frutos por planta (NFP) foi produzido quando o gergelim foi cultivado em monocultivo com 79,70 frutos por planta (Figura 3B). Analisando os sistemas consorciados, verifica-se redução de 62,4\% (29,97 frutos por planta) e $64,11 \%$ (28,60 frutos por planta) em relação ao monocultivo, respectivamente para a cv. IAC 2028 e BRS Nordestina.

Figura 3. Altura de inserção do primeiro fruto $(\mathrm{cm})(\mathrm{A})$, número de frutos por planta $(\mathrm{B})$, e produtividade de grãos $\left(\mathrm{kg}\right.$ ha $\left.{ }^{-1}\right)$ (E) do gergelim em diferentes sistemas de cultivo
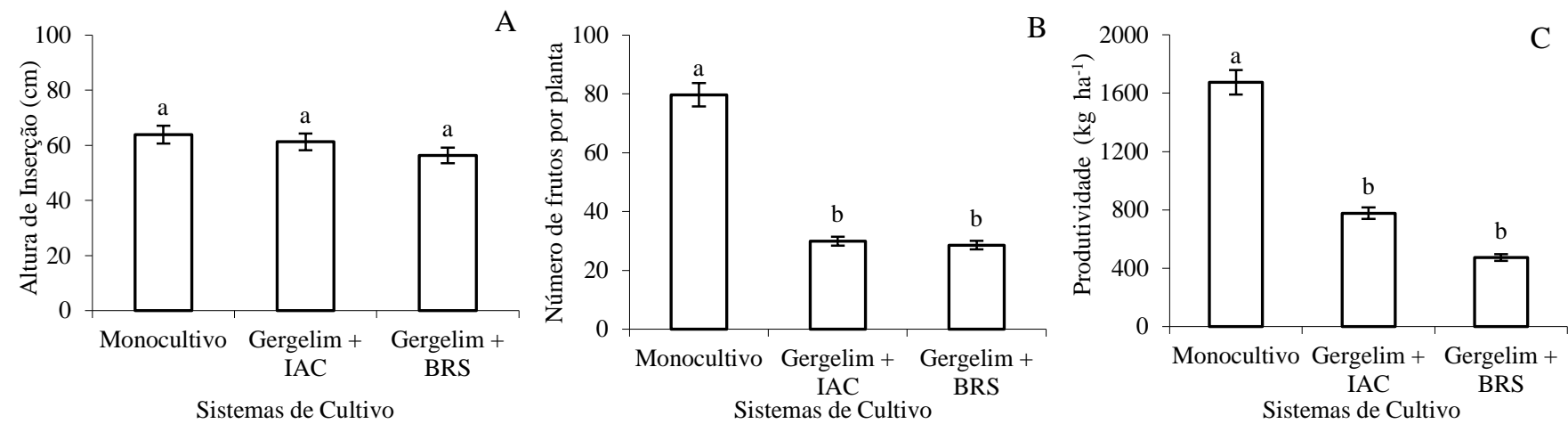

As letras diferentes em cada coluna indicam diferença estatística entre as médias do tratamento pelo teste de Tukey $(p \leq 0,05)$

De acordo com Távora et al. (2007) as plantas quando agrupadas no campo, competem entre si pelos fatores de crescimento e produção (luz, CO2, água e nutrientes minerais), o que consequentemente pode interferir em seu rendimento.

Assim como o número de frutos por planta a produtividade de grãos do gergelim também foi superior no sistema de monocultivo (1674,03 $\mathrm{kg} \mathrm{ha}^{-1}$ ) (Figura 3C). Esse resultado é superior aos obtidos por Silva et al. (2013) em estudo envolvendo sistemas de cultivos consorciados com gergelim no semiárido paraibano, os quais obtiveram em monocultivo, produtividade de $633,7 \mathrm{~kg} \mathrm{ha}^{-1}$. Com relação aos sistemas consorciados, verifica-se redução de 53,55\% $\left(777,50 \mathrm{~kg} \mathrm{ha}^{-1}\right)$ e $71,72 \%\left(443,38 \mathrm{~kg} \mathrm{ha}^{-1}\right)$, respectivamente para a cv. IAC 2028 e BRS Nordestina. Beltrão et al. (2010b) verificaram redução média de $38,46 \%$ na produção de grãos de gergelim quando consorciado com a mamoneira (cv. BRS Nordestina). Resultados semelhantes são reportados por Pinto et al. (2011) os quais obtiveram produtividade média do gergelim em consórcio com mamona de 535,67 kg ha-1. Observa-se ainda que a cv. BRS Nordestina promoveu a maior redução de produtividade do gergelim, confirmando mais uma vez a hipótese que essa cultivar é mais competitivo em relação a cv. IAC 2028. De acordo com Azevedo et al. (2007b) os rendimentos das culturas quando consorciadas tendem a reduzir, crescendo apenas com o aumento de sua população.

\section{CONCLUSÕES}

O consórcio com a mamoneira reduz os componentes de produção e consecutivamente de produtividade do feijãocaupi e gergelim, sendo a cv. BRS Nordestina mais competitiva.

Considerando as variáveis estudadas, a melhor opção para cultivo consorciado do feijão-caupi ou gergelim na região é a cv. IAC 2028.

\section{AGRADECIMENTO}

Ao CNPq e a Universidade Federal de Campina Grande (UFCG) pelo apoio e financiamento ao projeto e pela concessão das bolsas de iniciação científica e de produtividade. 


\section{REFERÊNCIAS}

ALBUQUERQUE, J. A. A.; OLIVA, L. S. C.; ALVES, J. M. A.; UCHÔA, S .C. P.; MELO, D. A. Cultivation of cassava and cowpea in intercropping systems held in Roraima's savannah, Brazil. Revista Ciência Agronômica, v.46, n.2, p.388-395, 2015.

ALIZADEH, Y.; KOOCHEKI, A.; NASSIRIMAHALLATI, M. Yield, yield components and potential weed control of intercropping bean (Phaseolus vulgaris L.) with sweet basil (Ocimum basilicum L.). Iranian Journal of Field Crops Research, v.7, n.2, p.541-553, 2009.

ARAúJO, A. C.; ALOUFA, M. A. I.; SILVA, A. J. N. S.; COSTA, A. A.; SANTOS, I. S. Análise não destrutiva de crescimento do gergelim consorciado com feijão caupi em sistema orgânico de cultivo. Revista Brasileira de Agroecologia, v.9, n.1, p.259-268, 2014.

AZEVEDO, D. M. P.; BELTRÃO, N. E. M.; SEVERINO, L. S.; SANTOS, J. W.; LEÃO, A. B. Arranjos de fileiras no consórcio mamoneira com milho no semiárido paraibano. Revista Brasileira de Oleaginosas e Fibrosas, v.11, n.2, p.97105, 2007a.

AZEVEDO, D. M. P.; BELTRÃO, N. E. M.; SEVERINO, L. S.; SANTOS, J. W.; LEÃO, A. B. Rendimento e Eficiência Agronômica do Consórcio da Mamoneira com Cereais e Feijão caupi no Semi-árido Nordestino. Revista Brasileira de Oleaginosas e Fibrosas, v.11, n.3, p.145-162, 2007 b.

BELTRÃO, B. A.; SOUZA JUNIOR, L. C.; MORAIS, F.; MENDES, V. A.; MIRANDA, J. L. F. Diagnóstico do município de Pombal. Projeto cadastro de fontes de abastecimento por água subterrânea. Recife: Ministério de Minas e Energia/CPRM/PRODEM. 2005. 23p.

BELTRÃO, N. E. M.; VALE, L. S.; MARQUES, L. F.; CARDOSO, G. D.; SOUTO, J. S. Consórcio mamona e amendoim: opção para a agricultura familiar. Revista Verde de Agroecologia e Desenvolvimento Sustentável, v.5, n.4, p.222-227, 2010a.

BELTRÃO, N. E. M.; VALE, L. S.; MARQUES, L. F.; CARDOSO, G. D.; MARACAJÁ, P. B. Época relativa de plantio no consórcio mamona e gergelim. Revista Verde de Agroecologia e Desenvolvimento Sustentável, v.5, n.5, p.67$73,2010 \mathrm{~b}$

BEZERRA, A. A. C.; TÁVORA, F. J. A. F.; FREIRE FILHO, F. R.; RIBEIRO, V. Q. Morfologia e produção de grãos em linhagens modernas de feijão-caupi submetidas a diferentes densidades populacionais. Revista de Biologia e Ciências da Terra, v.8, n.1, p.85-93, 2008.

BHATTI, I. H.; AHMAD, R.; JABBAR, A; NADEEM, M.; KHAN, M. M.; DIN, W. U. D.; VAINS, S. N. Agronomic performance of mash bean as an intercrop in sesame under different planting patterns. Emirates Journal of Agricultural Sciences, v.25, n.1, p.52-57, 2013.
BRASIL. Regras para análise de sementes. Ministério da Agricultura, Pecuária e Abastecimento. Secretaria de Defesa Agropecuária. Brasília: Mapa/ACS, 2009. 399 p.

CONAB. Companhia Nacional de Abastecimento. Acompanhamento da safra brasileira de grãos. 2011. Disponível em: http://www.conab.gov.br/. Acesso em: 22 Fev. 2014.

CORRÊA, M. L. P.; TÁVORA, F. J. A. F.; PITOMBEIRA. J. B. Comportamento de cultivares de mamona em sistemas de cultivo isolados e consorciados com caupi e sorgo granífero. Revista Ciência Agronômica, v.37, n.2, p.200-207, 2006.

COSCIONE, A. R.; BERTON, R. S. Barium extraction potential by mustard, sunflower and castor bean. Scientia Agricola, v.66, n.1, p.59-63, 2009.

COSTA, A. S. V.; SILVA, M. B. Sistemas de consórcio milho-feijão para a região do vale do Rio Doce, Minas Gerais. Ciência e Agrotecnologia, v.32, n.2, p.663-667, 2008.

COSTA, D. S.; BARBOSA, R. M.; SÁ, M. E. Sistemas de produção e cultivares de feijoeiro em consórcio com milho. Scientia Agraria, v.11, n.6, p.425-430, 2010.

DUTRA, A. F.; MELO, A. S.; DUTRA, W. F.; SILVA, F. G.; OLIVEIRA, I. M.; SUASSUNA, J. F.; VÉRAS NETO, J. G. Agronomic performance and profitability of castor bean (Ricinus communis L.) and peanut (Arachis hypogaea L.) intercropping in the Brazilian semiarid region. Australian Journal of Crop Science, v.9, n.2, p.120-126, 2015.

EMBRAPA. Centro Nacional de Pesquisa de Solos. Sistema Brasileiro de Classificação de Solos. 2 ed. Rio de Janeiro: Embrapa Solos, 2006.

EMATER. Empresa de Assistência Técnica e Extensão Rural. Precipitação pluvial na Paraíba. Campina Grande: EMATER, 2011.

FAO (Roma). FAOSTAT. 2013. Disponível em: http://faostat3.fao.org/faostat-

gateway/go/to/download/Q/QC/S. Acesso em: 25 Jun. 2014.

FERREIRA, D. F. Sisvar: a computer statistical analysis system. Ciência e Agrotecnologia, v.35, n.6, p.1039-1042, 2011.

FERREIRA, L. L.; BELTRÃO, N. E. M. (ed.) Aspectos fisiológicos e ecofisiológicos para a cultura do gergelim. In: BELTRÃO, N. E. M.; FERREIRA, L. L.; QUEIROZ, N. L.; TAVARES, M. S.; ROCHA, M. S.; ALENCAR, R. R.; PORTO, V. C. N. O gergelim e seu cultivo no semiárido brasileiro. Natal: IFRN, 2013. p.40-51.

IBGE. Produção agrícola municipal. 2011. Disponível em: http://www.sidra.ibge.gov.br/bda/tabelas. Acesso em: $06 \mathrm{Jul}$. 2014.

LAYANEZ-GARSABALL, J. A.; MÉNDEZ-NATERA, J. R. M. Efectos de extractos acuosos del follaje del corocillo (Cyperus rotundus L.) sobre la germinación de semillas y el 
crecimiento de plántulas de ajonjolí (Sesamum indicum L.) cv. Arapatol S-15. Idesia, v.24, n.2, p.61-75, 2006.

LITHOURGIDIS, A. S.; DORDAS, C. A.; DAMALAS, C. A.; VLACHOSTERGIOS, D. N. Annual intercrops: an alternative pathway for sustainable agriculture. Australian Journal of Crop Science, v.5, n.4, p.396-410, 2011.

OLIVEIRA FILHO, A. F.; BEZERRA, F. T. C.; PITOMBEIRA, J. B.; DUTRA, A. S.; BARROS, G. L. Eficiência agronômica e biológica nos consórcios da mamoneira com feijão-caupi ou milho. Revista Ciência Agronômica, v.47, n.4, p.729-736, 2016.

PEEL, M. C.; FINLAYSON, B. L.; MCMAHON, T. A. Updated world map of the Köppen-Geiger climate classification. Hydrology and Earth System Sciences Discussions, v.11, n.5, p1633-1644, 2007.

PEREIRA, J. R; BELTRÃO, N. E. M.; ARRIEL, N. H. C.; SILVA, E. S. B. Adubação orgânica do gergelim, no Seridó paraibano. Revista brasileira de oleaginosas e fibrosas, v.6, n.3, p.515-523, 2002.

PINTO, C. M.; SIZENANDO FILHO, F. A.; CYSNE, J. R. B.; PITOMBEIRA, J. B. Produtividade e índices competição da mamona consorciada com gergelim, algodão, milho e feijão caupi. Revista Verde de Agroecologia e Desenvolvimento Sustentável, v.6, n.2, p.75 - 85, 2011.

PORTES, T. A. Produção de feijão nos sistemas consorciados. Goiânia: Embrapa - CNPAF, 1996. 50 p.

ROCHA, M. M.; CARVALHO, K. J. M.; FREIRE FILHO, F. R.; LOPES, A. C. A.; GOMES, R. L. F.; SOUSA, I. S. Controle genético do comprimento do pedúnculo em feijãocaupi. Pesquisa Agropecuária Brasileira, v.44, n.3, p.270-275 2009.

SANTOS, J. F.; GRANGEIRO, J. I. T.; OLIVEIRA, M. E. C. Produção de cultivares de feijão-macáçar no Brejo paraibano. Revista Tecnologia \& Ciência Agropecuária, v.5, n.2, p.1721,2011

SILVA, G. S.; OLIVEIRA, R. A.; QUEIROZ, N. L.; SILVA, M. N. B.; SOUSA, M. F.; SILVA, S. A. Desempenho agronômico de algodão orgânico e oleaginosas consorciados com palma forrageira. Revista Brasileira de Engenharia Agrícola e Ambiental, v.17, n.9, p.975-981, 2013.

TÁVORA, F. J. A. F.; SILVA, C. S. A.; BLEICHER, E. Sistemas de consórcio do milho, sorgo e feijão-caupi em séries de substituição. Revista Brasileira Agrociência, v.13, n.3, p.311-317, 2007.

TEIXEIRA, I. R.; SILVA, G. C.; TIMOSSI, P. C.; SILVA, A. G. Desempenho agronômico de cultivares de feijão-comum consorciado com mamona. Revista Caatinga, v.24, n.4, p.5561, 2011.

UFC. Universidade Federal do Ceará. Recomendações de adubação e calagem para o Estado do Ceará. Fortaleza: UFC/CCA. 1993. 248p
WANG, Q.; WU, Y.; ZHAO, L.; CHEN, P.; TIAN, D. Research on Efficiency improving technology for intercropping sesame (Sesamun indicum) and peanut (Arachis hypogeae). Agricultural Science \& Technology, v.13, n.2, p.324-329, 2012. 